\title{
Impact of Minimum Tillage and Crop Rotation as Climate Change Adaptation Strategies on Farmer Welfare in Smallholder Farming Systems of Zambia
}

\author{
Elias Kuntashula ${ }^{1}$, Lydia M. Chabala ${ }^{2} \&$ Brian P. Mulenga ${ }^{3}$ \\ ${ }^{1}$ University of Zambia, Agricultural Economics \& Extension Department, Box 32379, Lusaka, Zambia \\ ${ }^{2}$ University of Zambia, Soil Science Department, Box 32379, Lusaka, Zambia \\ ${ }^{3}$ Indaba Agricultural Policy Research Institute, Plot No. 26A, Middleway Road, Lusaka Zambia \\ Correspondence: Elias Kuntashula, University of Zambia, Agricultural Economics \& Extension Department, \\ Box 32379, Lusaka, Zambia. Tel: 260-021-295-419. E-mail: ekuntashula@unza.zm
}

Received: April 16, 2014 Accepted: June 4, 2014 Online Published: July 31, 2014

doi:10.5539/jsd.v7n4p95 URL: http://dx.doi.org/10.5539/jsd.v7n4p95

\begin{abstract}
Worldwide, climate change is currently recognized as one of the major challenges to increased food production. The agriculture sector is the main source of livelihoods, growth and foreign exchange earnings in many developing countries including Zambia. However, it is also a sector that is mostly vulnerable to effects of climate change. Smallholder farmers in Zambia have been adopting agricultural related adaptation strategies including minimum tillage and crop rotation to mitigate effects of climate change. There has been contentious debate on whether the two strategies (that are elements of conservation farming) increase crop yields and incomes. Available literature heavily relies on biophysical experiments and show contradictions in the ability of these strategies to improve crop yields. Taking cognizance of the differences in socioeconomic circumstances of the farmers, the purpose of this study was to estimate the impact of minimum tillage and crop rotation on maize yields and incomes for farmers adopting the strategies. The study used cross sectional data collected in 2012/13 from 1231 households across six districts of Zambia and applied propensity score matching techniques and Heckman's selection estimators to account for observed and unobserved heterogeneity between the adopters and non-adopters. The results showed that about 12 and $19 \%$ of the farmers have adopted minimum tillage and crop rotation respectively. The strategies improved on-farm maize productivity by about $26 \%$ to $38 \%$ for minimum tillage and $21 \%$ to $24 \%$ for crop rotation. Minimum tillage also improved total household maize production. On the other hand crop rotation did not significantly improve total maize production and gross income from the crop. This could reflect the small proportions of areas allocated to legumes versus the areas subsequently allocated to the maize crop during crop rotation. The impact of crop rotation on the staple maize crop could be boosted by encouraging farmers to increase the areas allocated to legumes. The legumes portfolio in the government sponsored input support programme should be increased. The results from this study generally confirm the potential direct role of agricultural related climate change adaptation strategies in improving crop productivity levels in small holder farming systems.
\end{abstract}

Keywords: adaptation strategy, climate change, crop rotation, minimum tillage, Zambia

\section{Introduction}

Worldwide, climate change is currently recognized as one of the major challenges to increased food production. The foremost driver to adequate food production is the agriculture sector. The agriculture sector is the main source of livelihoods, growth and foreign exchange earnings in developing countries that have agriculture-based economies. Interestingly the sector is also a source and sink of greenhouse gases thus making it all important in providing the seemingly polarizing livelihood provisioning and climate change mitigation roles. In most parts of sub Saharan Africa, agriculture has been recognized as one of the most critical sectors since it provides livelihood to the majority of the people. Sub Saharan African agriculture employs a majority of the total labour force, making the expected impact of climate change worse in this region. Zambia's economy is mainly dependent on the exploitation of natural resources. Thus changes in climate would ultimately affect major sectors such as agriculture which generates a fifth of the national GDP and employs about two thirds of the labour force. 
Climate change is expected to have negative impacts on food security and how the agricultural sector would develop in Zambia and many other developing countries. According to Hachileka and Vaatainen (2011) current efforts to mitigate climate change are not sufficient to stop future climate changes while the effects are already having a negative impact on the rural poor who are more vulnerable. The welfare of most rural farmers who mainly depend on agriculture for their livelihood has thus been compromised. Adaptation or changing agricultural practices to improve or maintain yields amidst the effects of climate change has therefore become increasingly paramount. Such modifications to agricultural or farming include the practicing of minimum tillage, crop rotation, crop diversification and changing planting dates, among others.

In Zambia, despite the recognition of the damaging effects of climate change and accompanying farmer adaptation strategies, there is thin empirical literature on the impacts of adaptation strategies on farmer welfare. To what extent these adaptation strategies are able to improve farmers' welfare remain unclear. Chintu et al., (2011) noted that several climate change agricultural adaptation strategies have had a positive effect on farmer welfare. However, the study is descriptive in nature and thus fails to precisely estimate by how much such strategies increase farmer welfare. Minimum tillage and crop rotation have been promoted as some elements of conservation farming since the early 1990s in the country. Although not primarily promoted as climate change adaptation strategies but mainly meant to address soil productivity losses and droughts (Tembo \& Hagglabe, 2003), there is increasing evidence (Serigne et al., 2006; Deressa et al., 2008; Nyanga et al., 2011) that conservation farming (or some elements of it) is being used as an adaptation strategy.

Farmers on their own since time in memorial have been practicing crop rotation as a crop production improving strategy. Therefore both conventional agricultural extension systems and participatory farmer interactions have helped towards promoting minimum tillage and crop rotation as climate change adaptation strategies or interventions that could improve farmer welfare amidst changes in climate. Minimum tillage is a farming practice that involves reducing tillage operations to the minimum required for crop development (Siachinji, 1999) in order to foster rain water harvesting and nitrogen fixation by leguminous plants (CFU, 2007). Crop rotation involves the successively switching of crops allocated to particular fields mainly to preserve the productive capacity of the soil. In maize growing belts of Zambia, it is highly recommended that the switching involves some nitrogen fixing leguminous crops such as groundnuts, soybeans and others (CFU, 2007).

There have not been many studies that have precisely estimated the impact of minimum tillage and crop rotation on welfare outcome variables such as crop yield and income in Zambia. There are studies (Haggblade \& Tembo, 2003; CFU, 2007; Agricultural Consultative Forum, 2008) that have reported on conservation farming adoption rates perhaps reflecting the importance of the issue of numbers in most donor promoted interventions. These studies estimate that adoption rates of some form of conservation farming was around $10 \%$. There are also studies done in Zambia and elsewhere (Chomba, 2004; Haggblade \& Tembo, 2003; Kassie et al., 2002; Keyser \& Mwanza, 1996; Langmead, 2001; Pieri et al., 2002; Twomlow \& Hove, 2006) that indicate that conservation farming directly improve crop yields and reduce risks of crop failure. However, there are other studies (Nyangena \& Kohlin, 2008; Place \& Hazell, 1993) that observe that returns and crop productivity from conservation are lower than from non conservation farming practices. Notwithstanding the above contradictions, the major limitation in most of these studies is over reliance on experimental type of research designs that do not take cognizance of the socioeconomic circumstances of the farmers. Farmers in a real world face a lot of socioeconomic constraints that would affect the performance of a technology in an optimal way. Therefore accounting for both observed and unobserved heterogeneity in various socioeconomic as well as biophysical characteristics between farmers and farms that have adopted conservation farming (or some of its elements) and those that have not, is pertinent.

Therefore, the purpose of this study was to isolate the impact of minimum tillage and crop rotation for farmers and/or farms who adopted the technologies in response to decline in crop yields. Although farmers were explicitly asked to outline the adaptation strategies they have adopted due to effects of climate change, we are cognizant that decline in crop yields could also stem from other factors such as decline in soil productivity due to continuous cropping. Although there are other climate change strategies such as practicing agroforestry, changing area of land cultivated etc that were cited by farmers, this study reports only on minimum tillage and crop rotation, two principle elements of conservation farming. The other strategies are reported elsewhere. The study contributes to literature by giving precise estimates on the contribution of the two elements of conservation farming to farmer welfare through the use of well grounded identification strategies that account for differences in characteristics that also affect welfare. In this study we controlled for effects due to observable differences through matching strategies, and endogeneity bias that may potentially arise due to correlation of the unobserved heterogeneity and observed differences through use of Heckman's selection estimator. As a secondary contribution, the study gives more recent adoption rates of elements of conservation farming in selected areas of Zambia. 
The paper is structured as follows: study area and data used immediately follow this introduction. Then the paper discusses the theoretical frameworks on propensity score matching and Heckman's selection estimator. After this, the paper gives the results that are discussed in the subsequent section. Finally conclusions are drawn based on the findings of the study.

\section{Method}

\subsection{Study Areas and Data Sources}

The study covered six districts: two from the northern region (Serenje and Mpika districts), two from the southern region (Sinazongwe and Choma districts), and two from the eastern region (Petauke and Nyimba districts) of Zambia. The districts were purposely selected to reflect the different farming systems and agroecological regions of the country (Figure 1).

In 2012, Indaba Agricultural Policy Research Institute (IAPRI) formerly Food Security Research Project (FSRP) conducted a nationally representative household survey to form a panel that would be interviewed every four years under the Rural Agricultural Livelihood Survey (RALS) project. The first interviews under RALS took place during the second part of 2012. During this period our research team focusing mainly on climate change related issues increased the numbers of households in the selected districts by interviewing extra households using the same RALS questionnaire. The additional households were selected with the help of IAPRI and Zambia's Central Statistical Office personnel using the same random procedures employed when selecting the panel. The expanded sample from the six districts was 1600 with 1080 households coming from the panel.

In early 2013 the 1600 IAPRI expanded sample was targeted with a semi-structured questionnaire with specific issues that cover climate change. The broad issues covered in this supplemental survey included; smallholder farmers' perceptions about climate change, mitigation and adaption against climate change disasters, yields and incomes from entrepreneurial and agricultural activities in the previous farming season. Due to limited time and other logistical problems a total of 1231 (out of the 1600) households from the six districts were successfully re-interviewed. Socioeconomic and demographic data from RALS for these 1231 households was merged with the data from the climate change supplemental survey. This combined data set formed the core of the results reported in this study.

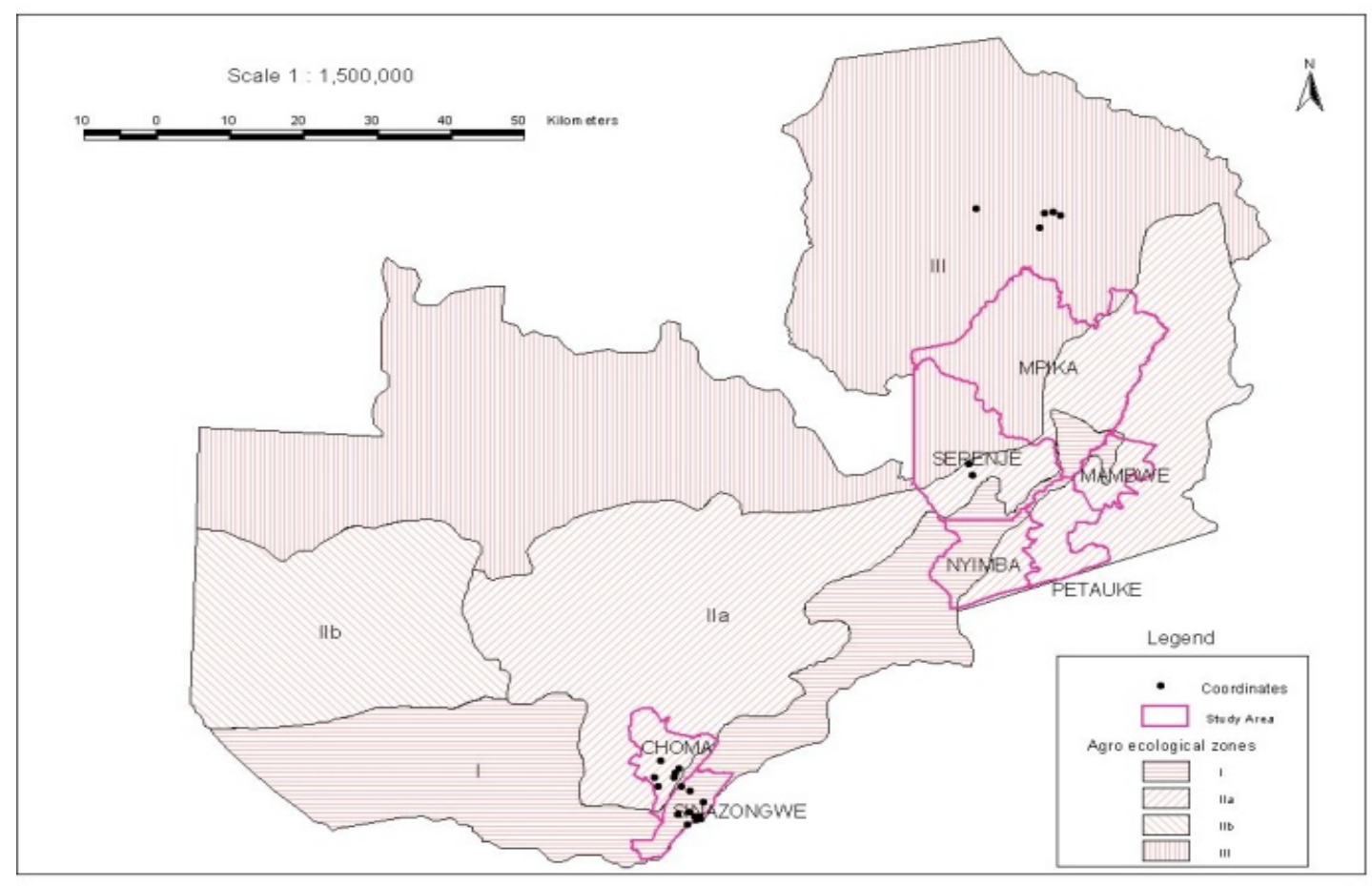

Figure 1. Map of Zambia showing selected survey districts and agroecological regions

Source: Chabala et al., 2013. 


\subsection{Analytical Frameworks and Estimation Techniques}

\subsubsection{Propensity Score Matching}

The study used the potential outcome framework for causal inference discussed by Rubin (1974) to estimate the Average Treatment effect on the Treated (ATT) or adopters of either minimum tillage or crop rotation on the welfare outcome. The welfare outcome variables analysed and reported in this study are based on the country's staple crop, maize, which is grown by almost all small scale farmers in Zambia. Specifically, we estimated the impact of these strategies on log of maize yield per hectare, household total maize production and gross income from maize. Rubin (1974) outcome framework to estimate the ATT postulates the following:

$$
E\left(Y_{1}-Y_{0} \backslash T=1\right)
$$

Where; $E$ is the expectation in the difference in the outcome $\left(Y_{l}-Y_{0}\right)$ between receiving treatment or adapting to climate change, $\mathrm{T}=1$ and the counter factual outcome if treatment or the particular technology had not been embraced $\mathrm{T}=0$. One possible identification strategy is to impose the Conditional Independent Assumption (CIA) that states that, given a set of observable covariates $\mathrm{X}$, the potential outcome in case of no treatment or not adopting is independent of treatment or technology assignment:

$$
Y_{0} \amalg T \backslash(X)
$$

Besides the CIA, a further requirement for identification is the common support or overlap condition, which ensures that for each treated or adapting household there are control or non-adapting households with the same observables. With the above two conditions, within each cell defined by $X$, treatment or technology adaptation assignment is random, and the outcome of control households can be used to estimate the counter factual outcome of the treated in the case of no treatment.

Matching on every covariate is difficult to implement when the set of covariates is large. To overcome the curse of dimensionality, Rosenbaum and Rubin (1983) show that matching on a single index, the propensity score (PS), rather than on a multidimensional covariate vector is possible. According to Heckman et al. (1998), the propensity score is defined as the conditional probability of receiving treatment or in this case of adopting the climate change adaptation strategy. Mathematically, the propensity score can be expressed as:

$$
e(x)=\operatorname{Pr}\left(W_{i}^{a}=1 \backslash X_{i}=x\right)=E\left[W_{i}^{a} \backslash X_{i}=x\right]
$$

Where $W_{i}=1$, for the adapting households, and $W_{i}=0$, for non adapting households; a = the adaptation strategy or technology; and $X_{i}$ is the vector of treatment covariates. The propensity score is usually unknown and this study estimated it through a probit regression in which the dependent variable equalled one if the household adopted minimum tillage and/or crop rotation and zero otherwise. This was followed by checking the balancing properties of the propensity scores. The balancing procedure tests whether or not adopter and non-adopter observations have the same distribution of propensity scores. Variables included in the PS estimation were those which were either correlated with both the outcome and treatment (adaptation strategy) or only correlated with the outcome and not the treatment variable (Brookhart et al., 2006). Various specifications of the probit model were attempted until the most complete and robust specification that satisfied the balancing tests and establishment of the common support region was obtained.

Matching was implemented using nearest neighbour with replacement and Epanechnikov kernel (bandwidth 0.06) matching techniques. For both techniques, the sample was bootstrapped 100 times. The use of the two approaches ensured checking robustness of the estimates. With nearest neighbour matching, the household from the comparison or control group is chosen as a matching partner for a treated household that is closest in terms of propensity score. With replacement meant that an untreated individual could be used more than once as a match. Matching with replacement increases the average quality of matching and decreases bias (Caliendo \& Kopeinig, 2008). Unlike the nearest neighbour matching algorithm that ensures only a few observations from the comparison group are used to construct the counterfactual outcome of the treated households, Kernel Matching (KM) uses weighted averages of all households in the control group to construct the counterfactual outcome. KM is therefore associated with lower variance because more information is used. One drawback of this approach is the possibility of using bad matches. It is for this reason that the proper imposition of the common support condition is of major importance for KM (Caliendo \& Kopeinig, 2008). 


\subsubsection{Heckman Selection Estimator}

The matching strategies discussed above account for selection bias due to observables. Using matched observations fulfilling the common support condition, we involved the use of the Heckman selection estimator to account for endogeneity or selection bias due to unobservables. According to Brundell and Dias (2000) this evaluation method is more robust although it also demands more assumptions about the structure of the model. The rationale of this estimator is to control directly for the part of the error term in the outcome equation that is correlated with the treatment or adoption dummy variable (Brunbell \& Dias, 2000). The Heckman procedure follows two steps. First, the part of the error term that is correlated with adoption is estimated. The estimated part is then included in the outcome equation and the effect of adoption is estimated in a second step. By construction, what remains of the error term in the outcome equation is not correlated with the adoption or participation decision. This model ably accounts for sample selection bias but the use of the two step procedure requires some adjustments to derive consistent standard errors (Maddala, 1983).

Following Heckman and Robb Jr. (1985), assume that a farmer experiences only one opportunity in time period $k$ to adopt a climate change adaptation strategy. Denoting welfare outcome of farmer $i$ in period $t$ by $Y_{i t}$, we note that this outcome is dependent on a vector of observed characteristics, $X_{i t}$. Post adoption outcome $(t>k)$ also depends on a dummy variable $d_{i}$, which equals 1 if the $i^{\text {th }}$ farmer adopts and 0 if he does not. Let $u_{i t}$ represent the error term in the outcome equation and assume $E\left[\mu_{i t}\right]=0$. Therefore;

$$
\begin{aligned}
Y_{i t}= & X_{i t} \beta+d_{i} \alpha+\mu_{i t}, & & t>k, \\
& =X_{i t} \beta+\mu_{i t}, & & t \leq k,
\end{aligned}
$$

Where $\beta$ and $\alpha$ are parameters, and $X_{i t}$ is assumed to be uncorrelated with $u_{i t}$. If there are endogeneity problems or selection bias then $d_{i}$ and $u_{i t}$ are correlated and the estimates from equation 1 will be inconsistent. The decision to adopt an adaptation strategy may be determined by a prospective farmer, agricultural administrators or both. The rule that a farmer makes to adopt can be described in terms of an index function framework. Let $I N_{i}$ be an index of benefits to the appropriate decision makers from adapting to climate change. It is a function of observed $Z_{i}$ and unobserved $V_{i}$ variables. Therefore we have;

$$
I N_{i}=Z_{i} \gamma+V_{i}
$$

For this function, $d_{i}=1$ if $I N_{i}>0$ and $d_{i}=0$ otherwise.

The distribution function of $V_{i}$ is denoted as $F\left(v_{i}\right)=\operatorname{Pr}\left(V_{i}<v_{i}\right) . V_{i}$ is assumed to be independently and identically distributed across persons. Let $p=E\left[d_{i}\right]=\operatorname{Pr}\left[d_{i}=1\right]$ and assume $1>\mathrm{p}>0$. The problem arises when adoption of the strategy is not random with respect to the disturbance in the outcome function. More specifically, if $E\left[u_{i t} d_{i}\right] \neq 0$. This may occur because of stochastic dependence between $u_{i t}$ and the unobservable $V_{i}$ (selection on unobservables) or because of stochastic dependence between $u_{i t}$ and $Z_{i}$ (selection on the observables).

All what is required to identify $\alpha$ in cross section data like ours is access to a regressor in (5). In the absence of a regressor, assumptions about the marginal distribution of $u_{i t}$ can produce consistent estimators of the impact of adopting adaption strategies. Details of how this can be done and the underlying assumptions are ably covered in Heckman and Robb Jr. (1985). We used stata version 11 to implement both propensity score matching and Heckman's selection techniques.

\section{Results and Discussions}

\subsection{Demographic Characteristics of Households}

The descriptive statistics of the sample households are presented in Table 1. Most rural households depend on family labour for various farm activities and therefore, the size of the household has an impact on labour supply hence adoption of certain strategies. The average household size was about 6.1. Similar estimates distributed around the overall average figures were obtained for the specific districts (Table 1).

Age of the household head has an impact on the productive capacity and adopting various climate change strategies. The estimated mean age of the households head in the sample was about 46 years. Age analysis at district level showed some significant differences between Choma and Sinazongwe. The mean age for household heads in Choma was almost 49 years while for those in Sinazongwe it was about 44 years. The other districts recorded average household head age of around the mean. This age profile means that the majority of the household heads were people predominantly below midlife and could be regarded as potentially productive 
farmers with capacity to adopt and adapt new farming practices to mitigate the vulgaries of climate change.

About $86 \%$ of those interviewed had some formal education. Of these, $57 \%$ had primary education and $37 \%$ had secondary education. About 3\% reported that they had post secondary education. All districts except Petauke had about or more than $85 \%$ of household heads who had attended some form of formal training. Petauke had a high proportion of household heads that had never been to school followed by Nyimba, Sinazongwe, Serenje, Mpika and Choma in that order (Table 1).

Whether the household is female or male headed and marital status of such households has implication on the availability of resources to undertake certain agricultural activities. Generally most female headed households have limited resources to adopt certain agricultural practices that could be adaptive to vulgaries of climate change. The overall sample comprised about $20 \%$ female headed households. For the specific districts, there were more male headed households in Choma followed by Petauke, Serenje, Sinazongwe, Nyimba and Mpika, in that order. With respect to marital status, $74 \%$ of the household heads were monogamously married, $7 \%$ were polygamously married, $12 \%$ were widowed, $4 \%$ were divorced and the rest were separated $(1 \%)$, never married $(1 \%)$ and cohabiting $(0.1 \%)$. More households in the southern region (Choma and Sinazongwe) were polygamously married perhaps reflecting the cultural practices of the mainly Tonga speaking people inhabiting this region (Table 1).

Table 1. Descriptive statistics of sampled households

\begin{tabular}{|c|c|c|c|c|c|c|c|}
\hline & \multicolumn{6}{|c|}{ District } & \multirow[b]{2}{*}{ Whole sample } \\
\hline & Choma & Sinazongwe & Serenje & Mpika & Nyimba & Petauke & \\
\hline \multicolumn{8}{|l|}{ Household size } \\
\hline Mean & $6.6(0.22)$ & $6.0(0.19)$ & $6.7(0.20)$ & $6.1(0.16)$ & $6.2(0.14)$ & $5.5(0.13)$ & $6.1(0.07)$ \\
\hline Range & $2-18$ & $1-12$ & $1-13$ & $1-14$ & $2-18$ & $1-13$ & $1-18$ \\
\hline Age of head & $48.9(1.16)$ & $43.6(1.23)$ & $46.3(1.29)$ & $47.3(1.06)$ & $45.1(0.86)$ & $46.4(0.88)$ & $46.3(0.43)$ \\
\hline Female headed (\%) & 16.4 & 20.8 & 19.0 & 21.8 & 21.4 & 17.6 & 19.6 \\
\hline \multicolumn{8}{|c|}{ Education level of head (\%) } \\
\hline None & 2.6 & 10.8 & 5.6 & 4.5 & 15.4 & 28.2 & 13.6 \\
\hline Primary education & 64.5 & 56.7 & 57.0 & 55.0 & 55.4 & 57.7 & 57.4 \\
\hline Secondary & 27.6 & 27.5 & 35.9 & 37.3 & 28.8 & 11.9 & 26.6 \\
\hline Post-secondary & 5.3 & 5.0 & 1.4 & 3.2 & 0.4 & 2.2 & 2.5 \\
\hline \multicolumn{8}{|c|}{ Marital status of head (\%) } \\
\hline Never married & 2.6 & 2.5 & 0 & 0 & 1.4 & 0.3 & 1.0 \\
\hline Married - one wife & 64.5 & 59.2 & 80.3 & 75.9 & 76.5 & 77.2 & 73.8 \\
\hline More than one wife & 20.4 & 20.8 & 2.1 & 2.3 & 2.1 & 7.1 & 7.5 \\
\hline Cohabiting & 0 & 0 & 0 & 0 & 0.4 & 0 & 0.1 \\
\hline Divorced & 3.3 & 1.7 & 7.0 & 2.7 & 6.0 & 4.2 & 4.3 \\
\hline Separated & 0.7 & 1.7 & 0.7 & 2.3 & 1.4 & 1.0 & 1.3 \\
\hline Widowed & 8.6 & 14.2 & 9.9 & 16.8 & 12.3 & 10.3 & 12.0 \\
\hline
\end{tabular}

Source: RALS (2012) and climate change supplemental survey (2013), standard errors in parentheses

\subsection{Awareness of Climate Change and Its Consequences}

Several households surveyed were aware of the effects of climate change and its consequences. Overall estimates showed that $77.4 \%$ of the households in the sample were aware of the effects of climate change. However there was a marked difference on the levels of awareness among the districts. Over $90 \%$ of the households in Petauke (91.3\%) Serenje (89.4\%) and Mpika (87.7\%) were aware of climate change consequences. $75 \%$ of households in Sinazongwe, $66.4 \%$ in Choma and $54.7 \%$ in Nyimba were also aware of climate change and its consequences. More than $98 \%$ of the surveyed households have noticed changes in rainfall patterns between now and 10 years 
ago. Most (83\%) of the households have observed decreased amounts of rainfall over time while $10 \%$ have noticed the changes in timeliness of the rainy season. The rest were of the view that rainfall has increased over time. There has also been an observation by $81 \%$ of the surveyed households that temperatures have been changing between now and the last 10 years. About $70 \%$ of the households have observed that temperatures have been rising while $28 \%$ feel that the temperatures have been declining over time. The rest of the households feel that the temperatures have been varying between rising and lowering in the past 10 years.

The households' perceptions of the consequences of climate change are reflected in Table 2. The major consequence as revealed by the households is that associated with the decline in crop yields as a result of climate change. More than $90 \%$ of the households cited this consequence. Less than $50 \%$ of the households (in order of mostly cited) revealed that decrease in soil and water quality, increases in human and livestock diseases, decline in livestock stocks, difficulty in timing seasons, scarcity of pastures and increased weeds, were all consequences of climate change (Table 2).

Table 2. Households' perceptions of consequences of climate change

\begin{tabular}{llllllll}
\hline & \multicolumn{7}{c}{ District } \\
\cline { 2 - 6 } Percent households citing & Choma & Sinazongwe & Serenje & Mpika & Nyimba & Petauke & Whole sample \\
\hline Crop yield decline & 86.2 & 83.3 & 95.1 & 82.7 & 99.6 & 91.3 & 90.7 \\
Livestock decline & 21.1 & 1.7 & 2.1 & 11.4 & 28.1 & 42.6 & 22.3 \\
Difficult to time seasons & 10.5 & 0 & 2.1 & 6.8 & 62.5 & 1.9 & 17.7 \\
Increased weeds & 9.2 & 0.8 & 0.7 & 0.5 & 23.2 & 12.2 & 9.8 \\
Increased diseases & 22.4 & 3.3 & 1.4 & 3.2 & 37.5 & 42.6 & 23.3 \\
Decrease in soil quality & 28.9 & 0 & 0.7 & 3.6 & 55.1 & 31.4 & 25 \\
Decrease in water quality & 10.5 & 9.2 & 0.7 & 0 & 84.2 & 48.7 & 34.1 \\
Scarcity of pastures & 3.9 & 11.7 & 0 & 4.5 & 24.2 & 31.8 & 16.1 \\
$\mathrm{~N}$ & 152 & 120 & 142 & 220 & 285 & 312 & 1231 \\
\hline
\end{tabular}

Source: RALS (2012) and climate change supplemental survey (2013)

\subsection{Household Adoption of Minimum Tillage and Crop Rotation Adaptation Strategies}

Rural households engage in various livelihood strategies to earn a living. The main economic activity among the rural households of Zambia is farming or agriculture. When these livelihood strategies are threatened, the households usually attempt to find a way to ensure a sustained welfare. The surveyed households were asked to indicate what modifications or adaptations they have made to their farming practices as a result of effects of climate change. The proportions of households adopting minimum tillage and crop rotation are shown in Table 3. Minimum tillage and crop rotation were cited as major strategies by about 12 and $19 \%$ of the farmers. The proportion of households adopting these strategies varied among the districts. For minimum tillage, all the districts except Mpika had adoption rates around the overall figure of $12 \%$. In Mpika, only $1.4 \%$ of the surveyed households adopted minimum tillage. Petauke had more households (44\%) practising crop rotation. Nyimba was second with adoption rate of $22 \%$. Serenje had $17 \%$ while Choma had $8 \%$ adoption rate. Only 0.8 and $0.5 \%$ of households in Sinazongwe and Mpika respectively, adopted crop rotation. The low levels of households adopting both strategies in Mpika could reflect the extension messages bordered on the inefficacy of conservation farming as a whole package in agroecological region 3 of Zambia. According to Hageblade and Tembo (2003) region 3 receives above normal rainfall and could be unsuitable for practices such as minimum tillage that ensure moisture is concentrated in specific planting stations. 
Table 3. Proportion of households adopting minimum tillage and crop rotation as climate change adaptation strategies

\begin{tabular}{llllllll}
\hline & \multicolumn{7}{c}{ District } \\
\cline { 2 - 6 } & Choma & Sinazongwe & Serenje & Mpika & Nyimba & Petauke & Whole sample \\
\hline Minimum tillage & 14.5 & 9.2 & 12 & 1.4 & 18.9 & 12.2 & 11.8 \\
Crop rotation & 7.9 & 0.8 & 16.9 & 0.5 & 22.1 & 44.2 & 19.4 \\
Sample size (N) & 152 & 120 & 142 & 220 & 285 & 312 & 1231 \\
\hline
\end{tabular}

Source: RALS (2012) and climate change supplemental survey (2013)

\subsection{Propensity Score, Maize Yield and Income Impact Estimates for Adopting Minimum Tillage and Crop Rotation}

The definitions and descriptions of variables used in the estimation of the propensity scores and minimum tillage/crop rotation-outcome impact estimates are shown in Tables 4 and 5. Adopters of minimum tillage than non-adopters had more household heads that were male and married. The farm sizes for the adopters were also larger than their non-adopting counter parts. Most of them used draft power, had access to credit and agricultural information and were generally relatively wealthier than the non-adopters (Table 4).

Table 4. Definitions and descriptive statistics of variables used in estimating the propensity score and minimum tillage models

\begin{tabular}{llll}
\hline Variable & Definition/codes & Adopters & Non-adopters \\
\hline Age & Age of household head in years & $47.44(1.266)$ & $45.91(0.488)$ \\
Sex & 1 if household head is male, 0 otherwise & $0.91(0.026)$ & $0.81(0.013)^{* *}$ \\
Marital status & 1 if married, 0 otherwise & $0.84(0.032)$ & $0.74(0.014)^{*}$ \\
Educ & Level of education of household head (1 primary, 2 secondary, 3 tertiary) $)$ & $1.19(0.056)$ & $1.22(0.023)$ \\
Hsize & Number of household members & $6.00(0.209)$ & $6.10(0.680)$ \\
Farmsize & Size of farm in hectares & $4.54(0.336)$ & $2.85(0.125)^{* * *}$ \\
CFadvise & 1 if household received conservation farming advise, 0 otherwise & $0.71(0.040)$ & $0.64(0.016)$ \\
Labhire & 1 if household hired labour, 0 otherwise & $0.21(0.036)$ & $0.19(0.013)$ \\
AnimLab & 1 if household used animal labour, 0 otherwise & $0.56(0.044)$ & $0.36(0.016)^{* * *}$ \\
AccessC & 1 if household accessed credit, 0 otherwise & $0.21(0.036)$ & $0.14(0.011)^{* *}$ \\
InforAcc & 1 if household had access to extension, 0 otherwise & $0.98(0.011)$ & $0.94(0.008)^{* *}$ \\
MGroup & 1 if household belongs to agricultural group, 0 otherwise & $0.74(0.039)$ & $0.49(0.017)$ \\
Windex & Household wealth index computed following Langyintuo $(2008)$ & $0.75(0.106)$ & $0.0056(0.032)^{* * *}$ \\
\hline$* * *$ significant at $1 \% * * *$ significant at $5 \% * *$ significant at $10 \%$ & &
\end{tabular}

Like in the minimum tillage model, most adopters of crop rotation had more household heads that were male and married. The farm sizes for the adopters of crop rotation were also larger than those for the non-adopting households. Again most of the households who adopted crop rotations had access to draft power, credit and agricultural information and were generally relatively wealthier than the non-adopters. In addition, most of the households adopting crop rotations had received advice on conservation farming (Table 5). 
Table 5. Definitions and descriptive statistics of variables used in estimating the propensity score and crop rotation models

\begin{tabular}{llll}
\hline Variable & Definition/codes & Adopters & Non-adopters \\
\hline Age & Age of household head in years & $45.55(0.936)$ & $46.24(0.519)$ \\
Sex & 1 if household head is male, 0 otherwise & $0.86(0.024)$ & $0.82(0.013)^{*}$ \\
Marital status & 1 if married, 0 otherwise & $0.81(0.027)$ & $0.74(0.015)^{* *}$ \\
Educ & Level of education of household head (1 primary, 2 secondary, 3 tertiary) & $1.06(0.049)$ & $1.25(0.023)^{* * *}$ \\
Hsize & Number of household members & $5.75(0.175)$ & $6.17(0.082)^{* *}$ \\
Farmsize & Size of farm in hectares & $3.52(0.198)$ & $2.94(0.139)^{*}$ \\
CFadvise & 1 if household received conservation farming advise, 0 otherwise & $0.72(0.031)$ & $0.63(0.017)^{* *}$ \\
Labhire & 1 if household hired labour, 0 otherwise & $0.19(0.027)$ & $0.19(0.014)$ \\
AnimLab & 1 if household used animal labour, 0 otherwise & $0.50(0.035)$ & $0.35(0.017)^{* * *}$ \\
AccessC & 1 if household accessed credit, 0 otherwise & $0.40(0.034)$ & $0.08(0.009)^{* * *}$ \\
InforAcc & 1 if household had access to extension, 0 otherwise & $0.99(0.004)$ & $0.93(0.009)^{* * *}$ \\
MGroup & 1 if household belongs to agricultural group, 0 otherwise & $0.55(0.035)$ & $0.52(0.017)$ \\
Windex & Household wealth index computed following Langyintuo $(2008)$ & $0.40(0.069)$ & $0.02(0.035)^{* * *}$ \\
\hline
\end{tabular}

*** significant at $1 \% ; * *$ significant at $5 \% ; *$ significant at $10 \%$

\subsubsection{Propensity Score Estimates}

For minimum tillage, the conditional probability to adopt the strategy was positively influenced by access to draft power, group membership, wealth status of the household and being resident in Nyimba. Being domiciled in Mpika negatively influenced the conditional probability of adopting minimum tillage (Table 6).

The propensity or conditional probability to adopt crop rotation was significantly influenced by whether the household; hired labour, had access to credit and information. In addition, being a resident in Petauke also positively influenced the propensity to adopt crop rotation. However, being domiciled in Sinazongwe and Mpika negatively influenced the propensity to adopt crop rotation (Table 7). 
Table 6. Propensity score estimates of adopting minimum tillage

\begin{tabular}{lllll}
\hline Minimum tillage & Coefficient & Standard error & $\mathrm{Z}$ & $\mathrm{P}>|\mathrm{z}|$ \\
\hline logAge & 0.210 & 0.191 & 1.1 & 0.272 \\
Sex & -0.0937 & 0.296 & -0.32 & 0.751 \\
Educ2 & -0.112 & 0.090 & -1.24 & 0.214 \\
Mstatus & -0.152 & 0.111 & -1.37 & 0.169 \\
CFadvise & -0.0501 & 0.123 & -0.41 & 0.684 \\
Labhire & 0.0202 & 0.146 & 0.14 & 0.890 \\
AnimLab & $0.414^{* * *}$ & 0.134 & 3.09 & 0.002 \\
AccessC & 0.0154 & 0.155 & 0.1 & 0.921 \\
InforAcc & 0.307 & 0.369 & 0.83 & 0.406 \\
Mgroup & $0.243 *$ & 0.136 & 1.79 & 0.074 \\
Windex & $0.233^{* * *}$ & 0.0587 & 3.96 & 0.000 \\
Sinazongwe & -0.119 & 0.217 & -0.55 & 0.583 \\
Serenje & 0.246 & 0.225 & 1.09 & 0.274 \\
Mpika & $-0.650^{* *}$ & 0.285 & -2.28 & 0.023 \\
Nyimba & $0.557^{* * *}$ & 0.194 & 2.87 & 0.004 \\
Petauke & -0.145 & 0.180 & -0.81 & 0.418 \\
Constant & $-2.057^{* *}$ & 0.974 & -2.11 & 0.035 \\
\hline Observations & 1,033 & & & \\
LR chi2 & 121.28 & & & \\
Prob>chi2 & 0.0000 & & & \\
Pseudo R2 & 0.1559 & & & \\
\hline$* * *$ significant at $1 \% *$ significant at $5 \% ; *$ significant at $10 \%$ & & \\
& & & &
\end{tabular}

Table 7. Propensity score estimates of adopting crop rotations

\begin{tabular}{lllll}
\hline Crop rotation & Coefficient & Standard error & $\mathrm{Z}$ & $\mathrm{P}>|\mathrm{z}|$ \\
\hline Mstatus & -0.0664 & 0.0569 & -1.17 & 0.243 \\
Educ2 & 0.0106 & 0.0782 & 0.14 & 0.892 \\
Labhire & $0.221^{*}$ & 0.131 & 1.69 & 0.090 \\
AccessC & $0.769^{* * *}$ & 0.129 & 5.95 & 0.000 \\
InforAcc & $1.162^{* *}$ & 0.504 & 2.3 & 0.021 \\
Sinazongwe & $-0.722^{* * *}$ & 0.233 & -3.1 & 0.002 \\
Serenje & 0.0734 & 0.168 & 0.44 & 0.663 \\
Mpika & $-0.955^{* * *}$ & 0.229 & -4.17 & 0.000 \\
Petauke & $0.795^{* * *}$ & 0.127 & 6.25 & 0.000 \\
Constant & $-2.165^{* * *}$ & 0.561 & -3.86 & 0.000 \\
\hline Observations & 1,033 & & & \\
LR chi2 (9) & 255.99 & & & \\
Prob $>$ chi2 & 0.0000 & & & \\
Pseudo R2 & 0.2473 & & & \\
Log likelihood & -389.48 & & &
\end{tabular}




\subsubsection{Impact of Minimum Tillage and Crop Rotation on Maize Productivity}

The use of nearest neighbour matching approach showed that both minimum tillage and crop rotation had a positive and significant impact on maize yield per hectare. Practising minimum tillage increased maize productivity by $26 \%$ while crop rotation significantly increased maize productivity by $21 \%$ (Table 8 ).

The impact of minimum tillage and crop rotation on maize yield per hectare was confirmed through the use of kernel matching that used more control households. In this case, adopting minimum tillage increased maize productivity by $35 \%$ while crop rotation significantly increased maize productivity by $24 \%$ (Table 8 ).

Both nearest neighbour and kernel matching methods were consistent on the estimated impacts of minimum tillage and crop rotation on maize productivity. There was also a narrow variation in the estimates from both methods. It can thus be concluded that controlling for observable characteristics, minimum tillage and crop rotation would increase maize productivity by about 26 to $35 \%$ and 21 to $24 \%$ respectively.

Table 8. Impact of adaptation strategies on maize productivity (2011/12)

\begin{tabular}{llllll}
\hline Nearest neighbour & Number treated & Number control & ATT & Bootstrapped Standard Error* & T \\
\hline Minimum tillage & 145 & 117 & 0.265 & 0.108 & 2.449 \\
Crop rotation & 235 & 153 & 0.211 & 0.096 & 2.196 \\
Kernel matching & & & & \\
Minimum tillage & 145 & 1029 & 0.351 & 0.082 & 4.265 \\
Crop rotation & 235 & 880 & 0.244 & 0.070 & 3.496 \\
\hline
\end{tabular}

*standard errors bootstrapped 100 times

\subsubsection{Impact of Minimum Tillage and Crop Rotation on Total Maize Production}

Using the nearest neighbour matching method showed that minimum tillage and crop rotation could increase total household maize production by about $42 \%$ and $19 \%$ respectively. However, the result on crop rotation was not statistically significant. The use of the kernel matching method showed that the two strategies could increase total maize production by $47 \%$ and $15 \%$ respectively. Again the estimate on crop rotation was found to be statistically insignificant (Table 9).

We again find the estimations from the two methods consistent in terms of the narrow variations in the figures and the statistical tests. One of the plausible explanations behind the non-significance of crop rotation on total maize production could be because of the disproportionate allocation of the area between the legumes such as groundnuts and beans on one hand, and the maize crop on the other. Usually legumes are grown on small pieces of land relative to the subsequent or successive maize crop. There are two reinforcing factors contributing to growing of legumes on small pieces of land. The first is that they are not staple food crops therefore most households consume small amounts of the legumes. Secondly, unlike for maize, there is no assured market for legumes in the country therefore the households are not encouraged to grow more for sale.

Table 9. Impact of adaptation strategies on household total maize production (2011/2012)

\begin{tabular}{llllll}
\hline Nearest neighbour & Number treated & Number control & ATT & Bootstrapped Standard Error* & T \\
\hline Minimum tillage & 129 & 99 & 0.424 & 0.158 & 2.689 \\
Crop rotation & 207 & 138 & 0.186 & 0.160 & 1.157 \\
Kernel matching & & & & \\
Minimum tillage & 129 & 864 & 0.471 & 0.124 & 3.815 \\
Crop rotation & 207 & 669 & 0.150 & 0.095 & 1.572 \\
\hline
\end{tabular}

*standard errors bootstrapped 100 times

\subsubsection{Impact of Minimum Tillage and Crop Rotation on Maize Gross Income}

The nearest neighbour matching showed that both minimum tillage and crop rotation would not significantly 
increase gross earnings from maize. The kernel matching that used more control households showed that crop rotation would not increase maize gross earnings while minimum tillage would increase the earnings by about $56 \%$ (Table 10).

Selling maize, the staple food, is not the primary objective of most rural households in Zambia. Having adequate amounts of maize for home consumption is of paramount importance. Therefore it is not surprising to find that both minimum tillage and crop rotation have positive impact on maize productivity but can have insignificant impact on income stemming from the maize sold.

Table 10. Impact of adaptation strategies on maize gross earnings (2011/12)

\begin{tabular}{llllll}
\hline Nearest neighbour & Number treated & Number control & ATT & Bootstrapped Standard Error* & T \\
\hline Minimum tillage & 129 & 59 & 0.321 & 0.224 & 1.429 \\
Crop rotation & 207 & 97 & -0.152 & 0.216 & -0.704 \\
Kernel matching & & & & \\
Minimum tillage & 129 & 864 & 0.562 & 0.149 & 3.769 \\
Crop rotation & 207 & 669 & -0.164 & 0.186 & -0.882 \\
\hline
\end{tabular}

*standard error bootstrapped 100 times

\subsection{Impact of Minimum Tillage and Crop Rotation on Maize Productivity Using Heckman Selection Model}

The Heckman selection estimation results further showed that minimum tillage increased maize productivity. The increase in maize production per hectare was estimated at around $38 \%$. Although of secondary significance, we note in this study that factors such as age, being male headed household, having more education, being married, household size, hiring labour, embracing animal draught power, having access to information and being a member of an agricultural group significantly influenced maize productivity. In addition, compared to being domiciled in Choma households in Serenje, Mpika and Petauke were generally expected to have higher maize productivity levels (Table 11).

Crop rotation or switching crops was still found to have an effect on maize productivity when unobservable covariates were controlled for. Results from the Heckman selection estimation indicate that crop rotation would increase maize productivity levels by about $17 \%$. The other factors influencing maize productivity in the crop rotation model included age of the household head, the head being male, the head being married, higher education, household size, hiring labour, embracing animal labour, having access to information and being a member of an agricultural group. It was also estimated that households from Serenje, Mpika and Petauke would experience higher maize productivity than those from Choma (Table 10). 
Table 11. Impact of minimum tillage on maize productivity using Heckman selection model

\begin{tabular}{|c|c|c|c|c|}
\hline & Coefficient & Standard Error & Z & $\mathrm{p}>\mathrm{IzI}$ \\
\hline Minimum tillage & $0.377 * * *$ & 0.0839 & 4.49 & 0.000 \\
\hline logAge & $0.979 * * *$ & 0.0605 & 16.18 & 0.000 \\
\hline Sex & $0.833 * * *$ & 0.132 & 6.32 & 0.000 \\
\hline Educ2 & $0.230 * * *$ & 0.0417 & 5.51 & 0.000 \\
\hline Mstatus & $0.273 * * *$ & 0.0492 & 5.55 & 0.000 \\
\hline $\operatorname{logHsize}$ & $0.306^{* * *}$ & 0.0594 & 5.15 & 0.000 \\
\hline CFadvise & $0.109 *$ & 0.0584 & 1.86 & 0.063 \\
\hline Labhire & $0.131^{*}$ & 0.0701 & 1.87 & 0.061 \\
\hline AnimLab & $0.185 * * *$ & 0.0671 & 2.75 & 0.006 \\
\hline AccessC & 0.0711 & 0.0813 & 0.88 & 0.381 \\
\hline InforAcc & $0.764 * * *$ & 0.127 & 6.01 & 0.000 \\
\hline Mgroup & $0.252 * * *$ & 0.0642 & 3.93 & 0.000 \\
\hline Windex & -0.0419 & 0.0337 & -1.25 & 0.213 \\
\hline Sinazongwe & $0.222 * *$ & 0.105 & 2.11 & 0.035 \\
\hline Serenje & $0.867 * * *$ & 0.112 & 7.71 & 0.000 \\
\hline Mpika & $0.863 * * *$ & 0.109 & 7.89 & 0.000 \\
\hline Nyimba & 0.0426 & 0.11 & 0.39 & 0.698 \\
\hline Petauke & $0.756^{* * *}$ & 0.0911 & 8.3 & 0.000 \\
\hline \multicolumn{5}{|l|}{ Select } \\
\hline logFarmsize & -0.425 & 0.297 & -1.43 & 0.153 \\
\hline $\log$ Age & 0.557 & 0.714 & 0.78 & 0.435 \\
\hline Sex & $1.788 * * *$ & 0.549 & 3.26 & 0.001 \\
\hline Educ2 & 0.0112 & 0.279 & 0.04 & 0.968 \\
\hline Mstatus & $0.408^{*}$ & 0.22 & 1.85 & 0.064 \\
\hline Windex & 0.0656 & 0.261 & 0.25 & 0.802 \\
\hline Constant & -1.436 & 2.766 & -0.52 & 0.604 \\
\hline Lambda & 0.181 & 0.129 & & \\
\hline Observations & 993 & & & \\
\hline Censored obs & 5 & & & \\
\hline Log likelihood & -1243.81 & & & \\
\hline Wald ch2(18) & 80599.26 & & & \\
\hline Prob > chi2 & 0.0000 & & & \\
\hline
\end{tabular}


Table 12. Impact of crop rotation on maize productivity using Heckman selection model

\begin{tabular}{|c|c|c|c|c|}
\hline Variable & Coefficient & Standard Error & Z & $\mathrm{P}>\mathrm{IzI}$ \\
\hline Crop rotation & $0.165^{* *}$ & 0.0729 & 2.26 & 0.024 \\
\hline logAge & $0.779 * * *$ & 0.0682 & 11.42 & 0.000 \\
\hline Sex & $0.704 * * *$ & 0.137 & 5.14 & 0.000 \\
\hline Mstatus & $0.237 * * *$ & 0.051 & 4.65 & 0.000 \\
\hline Educ2 & $0.203 * * *$ & 0.0416 & 4.87 & 0.000 \\
\hline $\operatorname{logHsize}$ & $0.238 * * *$ & 0.0591 & 4.03 & 0.000 \\
\hline CFadvise & 0.0840 & 0.0582 & 1.44 & 0.149 \\
\hline Labhire & $0.148^{* *}$ & 0.0692 & 2.14 & 0.032 \\
\hline AnimLab & $0.198 * * *$ & 0.0651 & 3.04 & 0.002 \\
\hline AccessC & 0.0113 & 0.0808 & 0.14 & 0.889 \\
\hline InforAcc & $1.952 * * *$ & 0.235 & 8.29 & 0.000 \\
\hline Mgroup & $0.244 * * *$ & 0.0633 & 3.86 & 0.000 \\
\hline Windex & 0.0194 & 0.0316 & 0.61 & 0.540 \\
\hline Sinazongwe & 0.135 & 0.105 & 1.28 & 0.200 \\
\hline Serenje & $0.805^{* * *}$ & 0.111 & 7.23 & 0.000 \\
\hline Mpika & $0.810 * * *$ & 0.109 & 7.45 & 0.000 \\
\hline Nyimba & 0.0537 & 0.105 & 0.51 & 0.610 \\
\hline Petauke & $0.655^{* * *}$ & 0.0919 & 7.13 & 0.000 \\
\hline \multicolumn{5}{|l|}{ Select } \\
\hline logFarmsize & -0.458 & 0.305 & -1.5 & 0.134 \\
\hline $\log$ Age & 0.487 & 0.707 & 0.69 & 0.491 \\
\hline Sex & $1.767 * * *$ & 0.549 & 3.22 & 0.001 \\
\hline Mstatus & $0.392 *$ & 0.225 & 1.74 & 0.081 \\
\hline Educ2 & -0.0108 & 0.276 & -0.04 & 0.969 \\
\hline Windex & 0.117 & 0.257 & 0.45 & 0.649 \\
\hline Cons & -1.0786 & 2.754 & -0.39 & 0.695 \\
\hline Lambda & 0.139 & 0.14 & & \\
\hline Observations & 952 & & & \\
\hline Censored obs & 5 & & & \\
\hline Log likelihood & -1166.49 & & & \\
\hline Wald ch2(18) & 81857 & & & \\
\hline Prob $>$ chi 2 & 0.0000 & & & \\
\hline
\end{tabular}

\section{Conclusions and Recommendations}

This study used household level data and applied propensity score matching techniques and Heckman's selection estimators to discern the impact of conservation farming practices, minimum tillage and crop rotation, on household maize productivity, total production and maize income. The two farming practices are promoted as soil productivity enhancing technologies as well as climate change adaptation strategies. Generally, the results show that both crop rotation and minimum tillage improved maize productivity. The improvement ranged from about $21 \%$ to $24 \%$ for crop rotation and $26 \%$ to $38 \%$ for minimum tillage. Minimum tillage also improved total maize production. On the other hand crop rotation did not significantly improve total maize production and gross income 
from the crop. This could reflect the small proportions of areas allocated to legumes versus the areas subsequently allocated to the maize crop. The impact of crop rotation on the staple maize crop could be boosted by encouraging farmers to increase the areas allocated to legumes. This could be done through the inclusion of legumes in the marketing portfolio of the quasi-public Food Reserve Agency, an institution that actively purchases maize from farmers. This would indirectly increase total maize production and thereby increasing the maize surplus for sale. The increase in areas allocated to legumes could also directly improve crop diversity and thus contribute to food security as well as increase cash income from crop sales. The impact results from this study generally confirm the potential direct role of agricultural related climate change adaptation strategies in improving crop productivity levels in small holder farming systems.

\section{Acknowledgements}

The Research team acknowledges financial support from Michigan State University and Administrative support from the University of Zambia. The team also acknowledges the many data collection assistants and the farmers who participated in the surveys. The support of the Indaba Agricultural Policy Research Institute (IAPRI) is also acknowledged.

\section{References}

Blundell, R., \& Dias, M. C. (2000). Evaluation methods for non-experimental data. Fiscal Studies, 21(4), 427-468. http://dx.doi.org/10.1111/j.1475-5890.2000.tb00031.x

Brookhart, M. A., Schneeweiss, S., Rothman, J. K., Glynn, J. R., Avorn, J., \& Sturmer, T. (2006). Variable Selection for Propensity Score Models. American Journal of Epidemiology, 163, 12. http://dx.doi.org/10.1093/aje/kwj149

Caliendo, M., \& Kopeinig, S. (2008). Some Practical Guidance for the Implementation of Propensity Score Matching. Journal of Economic Surveys, 1, 31-72. http://dx.doi.org/10.1111/j.1467-6419.2007.00527.x

Chabala, L. M., Kuntashula, E., \& Kaluba, P. (2013). Characterization of temporal changes in rainfall, temperature, flooding hazard and dry spells over Zambia. Universal Journal of Agricultural Research, 1(4), 134-144.

Chintu, R., Mutamba, E., Kaliba, L. M., Musyani, M. M., \& Yawe, A. (2011). The Impacts of climate change and coping strategies of small scale farmers in Central and Southern Zambia. In I. Mapaure, J. B. Mhango, \& D. K. Mulenga (Eds.), Mitigation and adaptation strategies to climate change. RAEIN_Africa Secretariate, John Meinert Printing (Pty) Ltd, Windhoek.

Chomba, G. (2004). Factors affecting smallholder farmers adoption of soil and water conservation practices in Zambia. (Unpublished master's thesis). Michigan State University.

Conservation Farming Unit (CFU). (2007). Conservation farming handbook for small holders in regions I and II. Lusaka: ZNFU.

Conservation Farming Unit (CFU). (2009). ZNFU Conservation Farming Unit Annual Reports. Lusaka: ZNFU CFU.

Deressa, T., Hassan, R. M., \& Ringler, C. (2008). Measuring Ethiopian Farmers' Vulnerability to Climate Change Across Regional States. IFPRI Discussion Paper 806. Washington, D.C.: International Food Policy Research Institute (IFPRI).

Hachileka, E., \& Vaatanen, S. (2011). Climate change and adaptation strategies in the Ciawa community in lower Zambezi. In I. Mapaure, J. B. Mhango, \& D. K. Mulenga (Eds.), Mitigation and adaptation strategies to climate change. RAEIN_Africa Secretariate, John Meinert Printing (Pty) Ltd, Windhoek.

Haggblade, S., \& Tembo, G. (2003). Development, Diffusion and Impact of Conservation Farming in Zambia. Lusaka, IFPRI and FSRP - MSU.

Heckman, J. J., \& Robb Jr, R. (1985). Alternative methods for evaluating the impact of interventions: An Overview. Journal of Econometrics, 30, 239-267. http://dx.doi.org/10.1016/0304-4076(85)90139-3

Heckman, J., Ichimura, H., Smith, J., \& Todd, P. (1998). Characterizing selection bias using experimental data. Econometrica, 66(5), 1017-1098. http://dx.doi.org/10.2307/2999630

Keyser, J., \& Mwanza, M. H. (1996). Conservation tillage. Lusaka, Zambia, The Institute of African Studies, University of Zambia.

Langmead, P. (2001). Does Conservation Farming Really Benefit Farmers? GART Yearbook 2001, 58-64. 
Langyintuo, A. S. (2008). Computing household wealth indices using principal components analysis method. Working Paper, Harare, Zimbabwe, CIMMYT.

Maddala, G. S. (1983). Limited dependent and qualitative variables in econometrics. Cambridge, U.K.: Cambridge University Press. http://dx.doi.org/10.1017/CBO9780511810176

Nyanga, P. H., Johnsen, F. H., Aune, J. B., \& Kalinda, T. H. (2011). Smallholder Farmers Perceptions of Climate Change and Conservation Agriculture: Evidence from Zambia. Journal of Sustainable Development, 4(4), 73-85. http://dx.doi.org/10.5539/jsd.v4n4p73

Nyangena, W., \& Köhlin, G. (2008). Estimating Returns to Soil and Water Conservation Investments. An Application to Crop Yield in Kenya. Environment for Development Discussion Paper Series. Economics for Development DP 08-32.

Pieri, C., Evers, G., Landers, J., O"Connell, P., \& Terry, E. (2002). No-Till Farming for Sustainable Rural Development. Agriculture and Rural Development Working Paper. Washington, DC 20433.

Rosenbaum, P., \& Rubin, D. (1983). The Central Role of the Propensity Score in Observational Studies for Causal Effects. Biometrika, 70, 41-55. http://dx.doi.org/10.1093/biomet/70.1.41

Rubin, D. (1974). Estimating Causal Effects of Treatments in Randomized and Non-randomized Studies. Journal of Educational Psychology, 66, 688-701. http://dx.doi.org/10.1037/h0037350

Serigne, T. K., Verchot, L., \& Mackensen, J. (2006). Climate Change and Variability in Southern Africa: Impacts and Adaptation in the Agricultural Sector. A publication by Word Agro forestry Centre (ICRAF) and United Nations Environment Programme (UNEP).

Siacinji, J. M. (1999). Residue retention in Zambia: Some technologies, indigenous methods and environmental issues. A resource book of the Animal Traction Network for Eastern and Southern Africa (ATNESA). Harare. Zimbabwe.

\section{Copyrights}

Copyright for this article is retained by the author(s), with first publication rights granted to the journal.

This is an open-access article distributed under the terms and conditions of the Creative Commons Attribution license (http://creativecommons.org/licenses/by/3.0/). 